Original Article

\title{
Study on Day Care Transfusion Services in Transfusion Medicine Department of a Tertiary Care Hospital
}

*Parvin $\mathrm{F}^{1}$, Islam $\mathrm{MA}^{2}$, Dipta $\mathrm{TF}^{3}$, Biswas $\mathrm{DA}^{4}$, Bhuiyan $\mathrm{F}^{5}$, Naznin $\mathrm{B}^{6}$, Wasim $\mathrm{M}^{7}$, Chowdhury $\mathrm{JR}^{8}$, Hasan $\mathrm{MN}^{9}$

\begin{abstract}
:
Transfusion of blood components and derivatives in day care unit is an eminent part of management of transfusion dependent patients. Day care transfusion service is an alternative to hospital admission and beneficial for those patients who receive blood more frequently for their survival. The aim of present study is to assess Transfusion Services provided in a Day Care Unit (DCU) of a tertiary care hospital. This study was carried out in DCU of Transfusion Medicine Department, Bangabandhu Sheikh Mujib Medical University, (BSMMU), in Dhaka during January to December 2014. Data were collected from record registers. Recorded retrospective data were analyzed as percentage and proportion. Total recipients were 718 . Among those 424 (59.05\%) were male and 294 (40.95\%) were female and
\end{abstract}

1. ${ }^{*}$ Dr. Farida Parvin, Assistant Professor, Department of Transfusion Medicine \& Clinical Haematology, BIRDEM General Hospital \& Ibrahim Medical College, Dhaka.

E-mail: dr.farida1984@gmail.com

2. Dr. Md. Ashadul Islam, Professor, Department of Transfusion Medicine, BSMMU, Dhaka.

3. Dr. Tashmim Farhana Dipta, Professor, Department of Transfusion Medicine \& Clinical Haematology, BIRDEM General Hospital \& Ibrahim Medical College, Dhaka

4. Dr. Danish Arefin Biswas, Associate Professor, Department of Transfusion Medicine, Sir Salimullah Medical College \& Mitford Hospital, Dhaka.

5. Dr. Fakruddin Bhuiyan, Professor, Department of Hematology, Sir Salimullah Medical College \& Mitford Hospital, Dhaka.

6. Dr. Bepasha Naznin, Transfusion Medicine Specialist, Department of Transfusion Medicine, Asgar Ali Hospital, Dhaka.

7. Dr. Md. Wasim, Medical Officer, Department of Transfusion Medicine, National Institute of Cardiovascular Diseases, Dhaka.

8. Romana Chowdhury, Phase-B, Resident, Dept. of Transfusion Medicine, BSMMU, Shahbag, Dhaka.

9. Dr. Md. Nazmul Hasan, Assistant professor, Dept. of Internal Medicine, BSMMU, Shahbag, Dhaka.

${ }^{*}$ For correspondence
562 (78.27\%) were between 10 to 40 years. A total of 8587 units of blood components were used during this period. Red Cell Concentrate was most commonly utilized product 6388 (74.39\%) followed by FFP 1360 (15.83\%), Platelet Concentrate 544 (6.33\%), Whole blood 260 (3.05\%) and Cryoprecipitate 35(0.40\%). Transfusion was required more frequently in thalassaemic 365(50.88\%) patients. Haemophilia $77(10.72 \%)$ and aplastic anaemia patients 49 (6.82\%) were next high. The main transfusion reaction observed during transfusion was febrile non-haemolytic reactions. For increasing use of specific blood product and hassle free transfusion services this kind of day care unit services should be strengthened. Long term study of this kind will help us to develop safe clinical transfusion practice.

Keywords: Transfusion Service, Day Care unit (DCU), Blood Components, Clinical transfusion practice

\section{INTRODUCTION}

Transfusion of blood component is one of the common therapeutic treatment both in outdoor and indoor settings. However, rational utilization of blood and its component widely varies in day to day practices in the hospital. Though it is proved by the evidence that potential harm can happen from unnecessary blood transfusions, it is seen that there is a generalized lack of compliance with appropriate transfusion guidelines as well as variation in clinical transfusion practice among different institutions and among individual physicians within the same institution. ${ }^{1}$ Effective use of blood and its components with high quality and minimum waste are important goals of blood utilization management system. ${ }^{2}$ In tertiary care hospitals blood transfusion day care service is an important part and also a helpful alternative to hospital admission for transfusion dependent patient. A day care transfusion service was unavailable in Bangladesh till 1990. In early 1990, the authorities of the Institute of Post graduate Medical and Research (IPGM\&R) Dhaka established the DCU within the Central Blood Transfusion department. DCU plays an important role for providing blood transfusions and monitoring the blood recipient during transfusion, especially for the patients who are waiting for long periods for hospital beds and need few units of blood components transfusion for their treatment. ${ }^{3}$ In DCU 
patient does not need to be admitted rather can receive blood as an outdoor patient. In Bangladesh one hospital bed is allotted for 3,151 people which is scarce. ${ }^{4}$ BSMMU is a multidiscipline postgraduate institute having 1600 beds hospital. The day care unit of Transfusion Department of BSMMU contains 16 beds and about twenty five to thirty numbers of recipients are getting blood transfusion per day without requiring any admission in the hospital. The patients and their relatives are happy for such kind of transfusion service in a day care unit ${ }^{5}$. In the present study all data of blood recipients in different clinical conditions attended in DCU were analyzed. All procedures were performed as per standard operating procedure (SOP). All blood components were transfused under supervision of physicians. The objective of this study is to assess transfusion services given in DCU of Transfusion Medicine Department in a tertiary care hospital.

The objectives of the study were:

a) To assess transfusion services given in DCU.

b) To find out the diseases in which DCU is a better choice for day care

c) To find out type of blood components and products which are more needed in DCU settings.

\section{MATERIALS AND METHODS}

During study period from January 2014 to December 2014, blood components transfused to all patients attending DCU were recorded in prescribed data like name, age, sex, blood group, clinical diagnosis, blood components used, adverse effects of transfusion and its managements. During blood transfusion every patient was carefully monitored by a physician. ABO grouping of blood recipient was determined by standard method with auto control. The types of blood components which were transfused in DCU were Whole blood (WB), Red cell concentrate (RCC), Fresh frozen plasma (FFP), Platelet Concentrate (PC) and Cryoprecipitate. No medication was used before or during transfusion.

\section{RESULTS}

In the present study, 718 blood recipients attended DCU of BSMMU for blood transfusion in 2014. Among which 424 (59.05\%) were male and 294 (40.95\%) were female. (Table I) Majority $562(78.27 \%)$ of recipients were between 10 to 40 years. (Table II) Transfusion was required more frequently in thalassaemic 365 (50.88\%) patients and other recipients were haemophilia, aplastic anaemia, leukaemia, undiagnosed anaemia, various malignancies (carcinoma breast, colon, lung, stomach), lymphoma, CKD, haemoglobinopathy, IDA, VWD and PNH were 77 (10.72\%),
$49(6.82 \%), 48(6.68 \%), 45(6.26 \%), 41(5.71 \%), 30$ (4.17\%), 25 (3.48\%), 12 (1.67\%), 11 (1.53\%), 8 (1.1\%), 7 $(0.97 \%)$ respectively. (Table-III) Total 8587 units of blood components were used during this period. Among them Red Cell Concentrate (RCC) was most commonly utilized product 6388(74.39\%) followed by FFP 1360 (15.83\%), Platelet Concentrate 544 (6.33\%), Whole blood, 260 (3.05\%) and Cryoprecipitate 35(0.40\%). (Fig- I ) RCC was mainly transfused in thalassaemia, leukaemia and undiagnosed anaemia cases. Fresh frozen plasma and Cryoprecipitate were used in patients of Hemophilia. Platelet concentrate was mainly used in leukaemic and aplastic anaemia patients. Whole blood was transfused mainly in carcinoma patient. The most common reaction observed during transfusion in day care was febrile non haemolytic reactions which were managed mostly by use of antipyretic.

Table I: Sex distribution of patients $(\mathbf{n}=718)$

\begin{tabular}{|l|c|c|}
\hline Sex & Number & Percentage \\
\hline Male & 424 & $59.05 \%$ \\
\hline Female & 294 & $40.95 \%$ \\
\hline
\end{tabular}

Table II: Age distribution of patients $(n=718)$

\begin{tabular}{|l|c|c|}
\hline Age(in years) & Number & Percentage \\
\hline $10-40$ & 562 & $78.27 \%$ \\
\hline $41-80$ & 156 & $21.73 \%$ \\
\hline
\end{tabular}

Table II: Distribution of patients according to diseases $(\mathbf{n}=718)$

\begin{tabular}{|l|c|c|}
\hline Diseases & Number & Percentage \\
\hline Thalassaemia & 365 & $50.88 \%$ \\
\hline Haemophilia & 77 & $10.72 \%$ \\
\hline Aplastic anaemia & 49 & $06.89 \%$ \\
\hline Leukaemia & 48 & $05.90 \%$ \\
\hline Malignancy & 41 & $05.78 \%$ \\
\hline Undiagnosed anaemia & 45 & $06.27 \%$ \\
\hline Chronic Kidney Disease & 25 & $02.95 \%$ \\
\hline Lymphoma & 30 & $01.85 \%$ \\
\hline Von Willibrands Disease & 08 & $00.62 \%$ \\
\hline Haemoglobinopathy & 12 & $00.74 \%$ \\
\hline Iron Deficiency Anemia & 12 & $01.48 \%$ \\
\hline $\begin{array}{l}\text { Paroxysmal Nocturnal } \\
\text { Hemoglobinuria }\end{array}$ & 03 & $00.37 \%$ \\
\hline Total & 718 & $100 \%$ \\
\hline
\end{tabular}




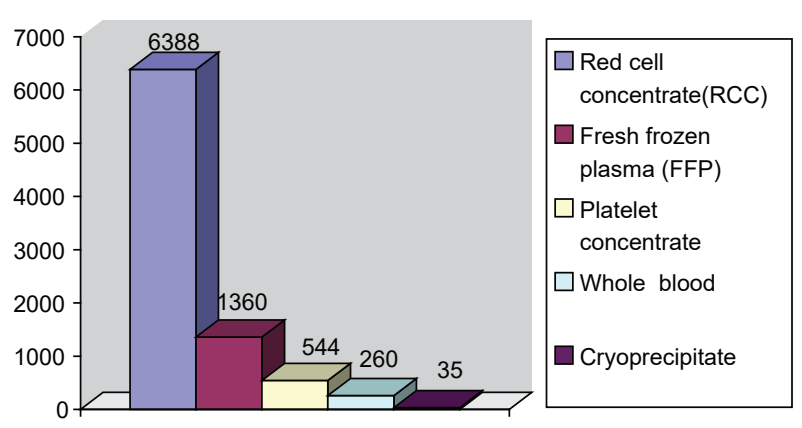

Figigure I : Distribution of blood components used ( $n=8587)$

\section{DISCUSSION}

Day care transfusion is essential for multitransfused patients due to life saving purpose. We have gone through previous studies in country and abroad. Kashem et al. ${ }^{6}$ reported that thalassaemia is an early childhood disease, so the age limit was $01-20$ years and found that $76(73.06 \%)$ were $B$ thalassemia with hemoglobin $\mathrm{E}$ and 13 (12.5\%) were aplastic anemia. There were six (5.77\%) leukemia patients also. The present study showed higher number of thalassaemic patients $(50.88 \%)$ getting transfusion which is similar to the Kashem et al. ${ }^{7}$ In his study, 548 (73.85\%) were suffering from malignancy and other disease were aplastic anaemia, thalassaemia, myeloproliferative disease, chronic kidney disease, dysfunctional uterine bleeding, severe anaemia due to unknown cause were 24 (3.23\%), 23 (3.099\%), 50 (6.73\%), 43 (5.79\%), 28 (3.77\%), 16 $(2.15 \%)$ respectively. The present study showed similar results in gender events. Karim et.al found that majority of the blood recipients were malignant $73.85 \%$ and this result varies with present study may be due to facilities for admission in $\mathrm{DMCH}$ of malignant patients. Islam et al. ${ }^{8}$ showed that out of 383 patients $47 \%$ (180) were suffering from anemia and $31.33 \%$ (120) were from carcinomas. Among those carcinomas (breast, colon, lung, larynx, tongue, stomach, esophagus and cholangiocarcinoma) were prevalent. Others such as chronic kidney disease and leukemia $7.31 \%$ (28) were next to take transfusion. The above findings are not comparable with the current study. The variation may be due to difference of disease modality. The study done by Shil et al. ${ }^{10}$ showed that among total 1569 blood \& blood components used in one year Packed red blood cell (PRBC) having the highest 1098 (69.98\%) and platelet rich plasma (PRP) having the lowest 07 $(0.45 \%$ requirement. Whole blood transfusion having second 254 (16.19\%) and fresh frozen plasma (FFP) 210 $(13.38 \%)$ third in terms of need. Packed red blood cell
(PRBC) transfused in thalassaemia (74\%), undiagnosed anemia $(7 \%)$. The main clinical condition in which fresh frozen plasma transfused is Hemophilia A (90\%). Fresh Whole blood transfusion $(16 \%)$ done in marrow aplasia $\&$ leukemia, which could be transfused with appropriate components. So the highest required component in the study of Shil et al was Red cell concentrate which was similar with current study. Begum et al. ${ }^{9}$ observed out of 516 units of blood components most of the patient received fresh whole blood 286 units (55\%) and some patient received different component like Packed Red cell, FFP and platelet concentrate 209 units (40.19\%), 18 units $(03.46 \%)$ and 03 units $(0.57 \%)$ respectively. The findings are not comparable with present study as number of patient and demand of component is increasing day by day. As WHO firmly prohibit single-unit transfusions in adults so, two-unit transfusions protocol are getting popular in clinical practice. Thus, many units of blood routinely ordered are not used and are kept in blood bank resulting in loss of shelf life and ultimately wastage of blood and its component. ${ }^{11,12}$

\section{CONCLUSIONS}

In the absence of an explicit maximum blood order policy in hospitals, ordering for blood transfusion is frequently based on subjective anticipation of blood loss instead of evidence-based estimates of average requirement in a particular procedure. Rational use of blood implies that right blood product is to be given to the patient only when needed and in the right amount. In our country perspective there is a great difficulty to provide better day care facilities for such a large number of patients due to adverse economic and social framework. It is also an important step to evaluate existing clinical transfusion practice and update the backdrop information related to blood transfusion practices for satisfactory day care transfusion services. Assessment of transfusion services in day care units should be done at a regular basis. This will help to provide information on pattern of usage of blood components and to build up national policy for better service to the patients.

\section{REFERENCES}

1. Fahmida Sharmin Chowdhury, Md Ali Ehsan Siddiqui, Khairul Islam ,Zubaida Nasreen, Husne Ara Begum, Hosne Ara Begum .Use of Blood and Blood components in Dhaka Medical College Hospital. Bangladesh Journal of Medicine, 2015 ;26:18-24 
2. Pozo EA, Rosales PM, Almeida-Neto Cd, Remesar MC, Cortes AD, et al. (2015) A comprehensive protocol to evaluate the use of blood and its components in Latin America and the Caribbean. Rev Panam Salud Publica 37: 435-41.

3. Haque KMG, Kabir KM, Sultan M, Dhaka, Bangladesh. Current Management Situation of Transfusion Dependent Thalassaemia Patients in Bangladesh: Experience of a Day Care Transfusion Unit. Transfusion Today, 1995; 23: 1015-76.

4. National Health Policy (Draft) 1999, Government of the Peoples Republic of Bangladesh, Ministry of Health \& Family Welfare (MOHFW).

5. Parvin F ,Islam A, DiptaTF, Afrose S, Dowllah IM, Ali M. Evaluation of most frequent Blood Recipient in Day Care Transfusion Unit in A Tertiary care Hospital -A Cross Sectional Study .Bangladesh Journal of Transfusion Medicine ,2016;4(2): 11-17

6. Kashem MA, Huda KM, Islam MA. Disease Pattern of Blood Recipients in a Day Care Transfusion Center. A Prospective Study in a Day Care Transfusion Center of Blood Transfusion Department, Bangabandhu Sheikh Mujib Medical University, (BSMMU), Dhaka, Bangladesh. SSMC J 2002; 8(2): 83-85.

7. Karim S, Hoque MM, Haque E, Dey SR, Begum HA. Management of various patients in day care transfusion center at transfusion medicine department of Dhaka Medical College Hospital, Dhaka - annual audit of 2013. J Dhaka Med Coll. 2014 ;23(2) :191-93.

8. Md. Ashadul Islam, Md. Abdul Quader, Khan Anisul Islam, Ayesha Khatun, Jolly Biswas. Daycare Transfusion Service: Two year Experience in a Day Care Transfusion Unit of a Licensed Private Blood Transfusion Center in Dhaka City of Bangladesh. Global Journal of Transfusion Medicine 2016;1(2): 75-7.

9. IA Begum, J Biswas, MA Fayez, MS Dowllah, S Begum. Current management in Day Care Transfusion unit at Dhaka Medical College Hospital. Chest and Heart Journal 2009; 33(1):37-40 .

10. Shill N, Biswas J, Islam A, Khatun A. Day care transfusion therapy one year experiences in a day care transfusion unit of transfusion medicine department in a tertiary care hospital. Bangladesh J Med 2005; 16:83-6.

11. World Health Organization. Blood safety and clinical technology: Strategy for Safe Blood Transfusion, Promoting and Practicing Rational Use of Blood. (Online) 2008 (Cited 2008 Jan 28).Available from URL: http://www.searo.who.int/ EN/Section10/ Section17/Section53/ Section478_1675.htm\# Practising.

12. Jayaranee S, Prathiba R, Vasanthi N, Lopez CG. An analysis of blood utilization for elective surgery in atertiary medical centre in Malaysia. Malays J Pathol 2002;24:59-66. 